\title{
Reduced sulfur trace gas exchange between a seasonally dry grassland and the atmosphere
}

\author{
Mary E. Whelan • Robert C. Rhew
}

Received: 17 November 2015/Accepted: 4 April 2016/Published online: 21 April 2016

(C) The Author(s) 2016. This article is published with open access at Springerlink.com

\begin{abstract}
Reduced sulfur gases are precursors to sulfate aerosols that act as cloud condensation nuclei and affect Earth's radiative balance. The diminishing anthropogenic atmospheric sulfur inputs due to longstanding acid rain abatement activities increase the influence of natural emissions on the remaining sulfur budget. Most previous terrestrial observations of reduced sulfur gas fluxes focus on wetland ecosystems where sulfur gas emissions are highest. The diffuse natural production of sulfur gas from more widespread oxic ecosystems needs to be characterized. Here we report in situ fluxes of sulfur gases and $\mathrm{CO}_{2}$ from grasslands outside of Santa Cruz, CA, USA $\left(36.96^{\circ} \mathrm{N}, 122.08^{\circ} \mathrm{W}\right)$. Monthly measurements were made using static flux
\end{abstract}

Responsible Editor: Edward Brzostek.

Electronic supplementary material The online version of this article (doi:10.1007/s10533-016-0207-7) contains supplementary material, which is available to authorized users.

\section{E. Whelan ( $\square)$}

Sierra Nevada Research Institute, University of California at Merced, 5200 North Lake Road, Merced, CA 95343, USA

e-mail: mwhelan2@ucmerced.edu

\section{R. C. Rhew}

Department of Geography and Berkeley Atmospheric Sciences Center, University of California at Berkeley, 507 McCone Hall \#4740, Berkeley, CA 94720, USA

e-mail: rrhew@berkeley.edu chambers from March 2012 to March 2014. A large net emission of dimethyl sulfide (DMS) was observed during the growing season. During the non-growing dry season, small but quantifiable carbonyl sulfide (COS) exchange rates were correlated with soil temperature. When soil moisture was artificially increased in senescent grassland plots, the relative exchange of $\mathrm{COS}: \mathrm{CO}_{2}$ increased and then returned to the original ratio within $2 \mathrm{~h}$. Sulfur gas fluxes during wet season soil moisture transition events (i.e. after precipitation) indicate that understudied aerobic environments may provide an important contribution to atmospheric COS consumption and DMS production.

Keywords Dimethyl sulfide - Carbon disulfide · Reduced sulfur compounds · Carbonyl sulfide $\cdot$ COS

\section{Introduction}

Atmospheric sulfur gas and aerosol emissions arise from human industry, volcanic activity, ocean bubble bursting, marine phytoplankton biological functions, aeolian processes, and net gas fluxes from terrestrial ecosystems (Watts 2000; Li et al. 2014; Alcolombri et al. 2015; Campbell et al. 2015). Reduced sulfur gases in the atmosphere are oxidized to form sulfate aerosol particles that greatly affect Earth's albedo and radiative balance (Charlson et al. 1987; Quinn and Bates 2011, Brühl et al. 2012). Carbonyl sulfide (COS) is the most abundant sulfur gas in non-urban air, with 
ambient concentrations around $500 \mathrm{ppt}$ and the longest lifetime of 2-7 years (Xu et al. 2002). Dimethyl sulfide (DMS) is thought to be responsible for a large portion of non-sea-salt atmospheric sulfate which can act as cloud condensation nuclei $(\mathrm{CCN})$, changing the lifetime and precipitation patterns of clouds (Andreae and Crutzen 1997).

Most terrestrial observations of reduced sulfur gas exchange have focused on wetlands because of the lower redox potential of wetland soils and consequent large magnitude fluxes (de Mello and Hines 1994; DeLaune et al. 2002; Whelan et al. 2013; Cooper and Saltzman 1987). However, terrestrial ecosystems with oxic soils cover an order of magnitude more surface area than wetlands. Recent research has demonstrated that oxic ecosystems can contribute important, though diffuse, amounts of biogenic sources of sulfate aerosol precursors. This includes DMS production in tropical rain forests (Andreae 1990; Jardine et al. 2015) and some agricultural crops (Fall et al. 1988), and COS emissions from a pine forest (White et al. 2010) and a wheat field (Billesbach et al. 2014).

Terrestrial plants can act as both a source and sink for reduced sulfur compounds. Generally, plants are a minor source of DMS to the atmosphere (Kanda et al. 1995; Geng and Mu 2006), and net DMS production from tropical tree species peaks during times of high temperature and photosynthetic radiation (Jardine et al. 2015). On the other hand, plant leaves are also the largest sink for COS in the troposphere (Protoschill-Krebs et al. 1996; Montzka et al. 2007; Notni et al. 2007; Campbell et al. 2008). COS is quickly and irreversibly hydrolyzed into $\mathrm{H}_{2} \mathrm{~S}$ and $\mathrm{CO}_{2}$ inside plant stomata via the enzymes involved in photosynthesis (Protoschill-Krebs et al. 1996). In many circumstances, this net uptake is a function of stomatal conductance (Stimler et al. 2010; Seibt et al. 2010) and can continue in the dark (Billesbach et al. 2014).

Both soil production and soil consumption of reduced sulfur compounds are strongly influenced by changes in water content and temperature (Watts 2000; Whelan et al. 2013). Water limits soil pore space exchange with the atmosphere, creating areas of low oxygen and low redox potential. DMS production by soils is strongly dependent on redox conditions and soil microbial community dynamics (Sparling and Searle 1993, Lomans et al. 2002). COS production from soils may also rely on redox potential (Devai and DeLaune 1995), though COS production has been recently observed in dry, oxic agricultural soils at high ambient temperatures (Maseyk et al. 2014; Whelan and Rhew 2015; Whelan et al. 2016). COS consumption has been related to microbial activity in soils (Yi et al. 2007) and appears to be mediated by the same enzyme implicated in plant uptake, carbonic anhydrase (Kesselmeier et al. 1999). Higher COS uptake is observed when the litter layer is preserved (Yi et al. 2007) and represents a relatively important sink of COS (Sun et al. 2016).

These prior studies suggest that temperature and water availability are two major environmental parameters that can affect plant and microbial activity with respect to reduced sulfur compound fluxes. In this study, we quantified the surface-atmosphere gas exchange of DMS, COS and $\mathrm{CS}_{2}$ in a mediterranean grassland in northern California in both the wet growing season and the dry non-growing season. The distinct dry and wet seasons and the annual grass cover allowed us to investigate the same sites over a range of temperatures and soil moistures, with and without living plant cover. We hypothesized that emissions of reduced sulfur compounds were triggered or mediated by changes in soil moisture conditions, similar to the pulses of other trace gases following rainfall. The pulse of inorganic nitrogen and $\mathrm{CO}_{2}$ released following the rewetting of dry soils is known as the "Birch Effect" (Birch 1958; Jarvis et al. 2007), a phenomenon likely to impact reduced sulfur gas emissions as well. Experimental rainfall manipulations were employed to determine the impact of soil moisture transitions on sulfur gas fluxes. Our experimental set up allowed us to quantify net fluxes of COS, DMS, and $\mathrm{CS}_{2}$ coincident with $\mathrm{CO}_{2}$ exchange. $\mathrm{H}_{2} \mathrm{~S}$ (hydrogen sulfide) and $\mathrm{CH}_{3} \mathrm{SH}$ (methane thiol) fluxes were also measured when possible.

\section{Materials and methods}

Flux measurements were performed every month except December from March 2012 to March 2013, with one additional outing on March 2014 (Table 1). To optimize the amount of useful information generated from a limited number of flux measurements, three sampling strategies were used to characterize (1) natural variation in situ of sulfur and carbon gas fluxes, (2) the change in fluxes over time from a single plot when rainfall was added or light conditions were 
Table 1 Summary of field outings: all outings took place in an annual grassland unless otherwise indicated

\begin{tabular}{|c|c|c|c|c|c|}
\hline Date & Sites & $\begin{array}{l}\text { Total \# flux } \\
\text { observations }\end{array}$ & Notes & $\begin{array}{l}\text { Average field soil } \\
\text { moisture (VWC \%) }\end{array}$ & $\begin{array}{l}\text { Additional soil } \\
\text { moisture from } \\
\text { added rainfall }\end{array}$ \\
\hline \multicolumn{6}{|l|}{2012} \\
\hline March 21 & 2 & 3 & Method evaluation & $26.1 \pm 2.8$ & 0 \\
\hline April 26 & 1 & 2 & Method evaluation & $18.2 \pm 3.3$ & 0 \\
\hline May 30 & 1 & 3 & No water added & $6.4 \pm 3.5$ & 0 \\
\hline June 26 & 2 & 4 & Water added & $4.4 \pm 1.4$ & $7.9 \pm 4.8$ \\
\hline June 28 & 2 & 4 & Water added & $2.4 \pm 1.8$ & $5.7 \pm 3.9$ \\
\hline July 3 & 2 & 4 & Water added, perennial grass site & $3.9 \pm 1.9$ & $7.0 \pm 4.1$ \\
\hline July 26 & 1 & 4 & Water added & $2.2 \pm 0.28$ & $6.9 \pm 1.3$ \\
\hline August 24 & 1 & 4 & Water added & $3.2 \pm 0.1$ & $6.5 \pm 6.5$ \\
\hline September 20 & 1 & 4 & Water added & $4.8 \pm 1.0$ & $6.6 \pm 5.4$ \\
\hline October 28 & 1 & 4 & Water added & $7.1 \pm 2.3$ & $2.8 \pm 4.9$ \\
\hline November 27 & 1 & 3 & Rained recently; no water added & $20.9 \pm 3.1$ & 0 \\
\hline \multicolumn{6}{|l|}{2013} \\
\hline January 24 & 1 & 3 & Experiment performed during rain storm & $34.8 \pm 8.4^{*}$ & $-11.9 \pm 8.8^{*}$ \\
\hline February 27 & 2 & 4 & Water added & $13.7 \pm 4.9$ & $2.5 \pm 5.7$ \\
\hline March 4 & 1 & 3 & Water added & $13.5 \pm 1.9$ & $6.1 \pm 4.4$ \\
\hline March 10 & 2 & 4 & Water added, perennial grass site & $21.9 \pm 4.9$ & $5.7 \pm 4.8$ \\
\hline \multicolumn{6}{|l|}{2014} \\
\hline March 13 & 1 & $8, \mathrm{COS}$ and $\mathrm{CO}_{2}$ only & Light/dark chamber evaluation & n.m. & 0 \\
\hline
\end{tabular}

* The January 24 outing took place during a rainstorm. The field soil moisture after several hours of rain was on average $11.9 \%$ VWC higher than the experimental plot soil moisture due to rainfall exclusion by the chamber lid

introduced and (3) the spatial variation of fluxes when rainfall was added by comparing 2 nearby plots in either an annual or perennial grassland site. All measurements were performed under dark conditions except for the final outing in 2014 that sought to compare gas fluxes under both light and dark conditions.

\section{Site description}

Coastal California experiences a mediterranean climate with warm, dry summers followed by cool, wet winters (Fig. S1); grasses have distinct growing and dormancy seasons. Soil profiles on uncultivated marine terraces near Santa Cruz, CA $\left(36.96^{\circ} \mathrm{N}\right.$, $122.08^{\circ} \mathrm{W}$ ) have been used as a "natural laboratory" for the study of weathering processes and marine terrace formation through well-instrumented research plots. Using the sites characterized in White et al. (2008), here we chose plots located on 3 marine terraces of differing ages, but with similar soil parent material. In Schulz et al. (2011), the sites are referred to as SCT2, SCT3, and SCT5. Two annual grassland sites, located within Wilder Ranch State Park, were dominated by invasive European C3 grasses with root depths of about $1 \mathrm{~m}$. One perennial grassland site dominated by native bunch grasses was on private land.

Static flux chambers

Static flux chambers (Livingston and Hutchinson 1995) were deployed to quantify grassland-atmospheric fluxes of sulfur-containing gases. First, a $0.4 \mathrm{~m} \times 0.4 \mathrm{~m} \times 0.23 \mathrm{~m} \quad$ PTFE-lined aluminum frame was installed at least $3 \mathrm{~cm}$ into the soil profile, taking care to minimize severing plant roots. After an hour to allow the plot to recover from the disturbance, a chamber lid was clamped to the chamber base to mark the beginning of the flux measurement, when $\mathrm{t}=0$. The lid was a clear Lexan plastic rectangular box $0.4 \mathrm{~m} \times 0.4 \mathrm{~m} \times 0.43 \mathrm{~m}$, lined internally with a $0.254 \mathrm{~mm}$ thick PTFE film (Fig. S2). Weather 
stripping was installed along the box lip between the Lexan and PTFE liner to aid in sealing the chamber lid to the base. The chamber lid and base enclosed a total of $109 \mathrm{~L}$, and the headspace was mixed by a PTFEcoated aluminum fan driven by an external motor. To avoid complications from photo-oxidation and rising temperatures within the chamber, the chamber lid was covered with reflective insulation. All flux measurements were performed in a dark chamber except for the light/dark chamber experiments on 13 March, 2014 (Table 1). Before deployment in the field, the chamber equipment was tested for chemical inertness under both ambient and elevated concentrations of COS and DMS in the chamber headspace; measured concentrations had an relative standard deviation of $3.5 \%$ over a $32 \mathrm{~min}$ incubation period, translating to a minimum detectable flux of $0.6 \mathrm{pmol} \mathrm{m} \mathrm{m}^{-2} \mathrm{~s}^{-1}$.

For each flux measurement, at least 3 whole air samples were collected at regular intervals through a silica-coated steel $2 \mu \mathrm{m}$ filter into previously-evacuated $1 \mathrm{~L}$ canisters lined with amorphous silicon (Restek, Bellefonte, PA) that have been shown to be appropriate for collection and storage of ambient-level sulfur-containing compounds (Khan et al. 2012). During collection, a short vent line was opened to the atmosphere to avoid under-pressurizing the chamber headspace. Along with canister sampling, $30 \mathrm{~mL}$ aliquot subsamples of the chamber headspace were collected in glass vials (Wheaton, Millville, NJ) for analysis of $\mathrm{CO}_{2}$. The number of flux measurements that could be made in one outing were limited by the number of appropriate air sampling flasks available for reduced sulfur gas sampling.

Flux chamber measurements were performed between 9:00 AM and 4:30 PM local time for each outing. The prevailing wind was from the ocean in the south, traveling over approximately $1.5 \mathrm{~km}$ of sparsely populated coastal farm and a two lane state highway. Temperatures were recorded outside the chambers and in approximately the middle of the chambers using stainless steel thermocouple dataloggers (iButtons, Maxim Inc., Sunnyvale, CA) wrapped in Teflon tape and suspended from the Teflon sampling line. Barometric pressure was measured throughout the experiment. Soil volumetric water content (\%VWC) at $5 \mathrm{~cm}$ depth was measured outside and within the experimental plot after air sampling for each outing (ThetaProbe, organic setting, Delta-T Devices, Cambridge, UK). The volume of the chamber headspace was determined by estimating plant volume and measuring soil volume from 16 depth measurements in the trough left by the chamber base after removal, then subtracting these volumes from the known volume of the chamber lid and base.

Quantification of gas samples

To quantify COS and DMS, $50 \mathrm{~mL}$ subsamples of air from the canisters were injected onto a GC column after cryo-focusing on a narrow bore silica-coated tube trap immersed in liquid nitrogen. Air samples were analyzed on an Agilent 7890A gas chromatograph attached to an Agilent 355 sulfur chemiluminescence detector (GC/SCD). The SCD is ideal for analysis of reduced sulfur compounds because of its high sensitivity and linear, equimolar response. All wetted surfaces were either PFA/PTFE or Siltek-treated stainless steel to minimize analyte loss. A five point calibration curve was generated before each outing using a whole air standard (COS concentration $=543$ parts-per-trillion) calibrated to the provisional scale of NOAA-SIO for COS. A calibration curve for DMS was created by diluting a $1 \mathrm{ppm}$ gas standard (Matheson Tri-Gas, Newark, CA) on a custom built dilution line and comparing it to the whole air calibration curve to confirm the equimolar detector response. The analytical detection limit for all gases investigated was 120 parts-per-trillion. More details on this method can be found in Khan et al. (2012).

$\mathrm{CO}_{2}$ gas in the Wheaton vial air samples was analyzed on a Shimadzu GC-14A with a thermal conductivity detector (TCD) (Shimadzu Scientific Inc., Columbia, MD). A 997 ppm CO 2 standard (Scott Specialty Gases) was quantified between every 10 unknown samples to determine concentration and correct for instrument drift. $\mathrm{CH}_{4}$ and $\mathrm{N}_{2} \mathrm{O}$ were also quantified in these aliquots, but no measurable fluxes were discovered.

\section{Calculation of fluxes}

The concentration of COS, DMS, and $\mathrm{CO}_{2}$ in the chamber headspace over time was used to calculate the overall flux from experimental field plots. A linear and an exponential model were both applied to data from each chamber, and the approach with better goodness of fit was assigned as the flux. Only experiments yielding fits with $\mathrm{r}^{2}>0.9$ were included in this study. 
This filtering excludes flux measurements that could not be detected because either concentrations were too low $(<120 \mathrm{ppt})$ or the concentration variation within the chamber due to a real flux was less than $3.5 \%$. The exponential flux model was adapted from de Mello and Hines (1994): the mole ratio at time t, C(t) is a function of the mole ratio in the headspace at time 0 $\left(\mathrm{C}_{0}\right)$, the concentration when soil pore space and chamber headspace are in equilibrium $\left(\mathrm{C}_{\max }\right)$, and a first order uptake rate constant $\mathrm{k}$ : $\mathrm{C}(\mathrm{t})=\mathrm{C}_{\max }$ $-\left(\mathrm{C}_{\max }-\mathrm{C}_{0}\right) \exp (-\mathrm{kt}) . \mathrm{C}_{\max }$ and $\mathrm{k}$ are solved iteratively, and the rate of mole ratio change is calculated for time $0,(\mathrm{dC} / \mathrm{dt})_{\mathrm{t}=0}=\mathrm{k}\left(\mathrm{C}_{\max }-\mathrm{C}_{0}\right)$. The trace gas flux $\mathrm{F}$ is then calculated by $\mathrm{F}=\left[\mathrm{n}_{\text {chamber }}(\mathrm{dC} /\right.$ $\left.\mathrm{dt})_{\mathrm{t}=0}\right] \mathrm{N}^{-1}$, where $\mathrm{n}_{\text {chamber }}$ is the number of moles in the chamber during sampling and $\mathrm{N}$ is the surface area of the chamber plot in $\mathrm{m}^{2}$. $\mathrm{CO}_{2}$ fluxes are reported in $\mu \mathrm{mol} \mathrm{m} \mathrm{m}^{-2} \mathrm{~s}^{-1}$. COS and DMS fluxes are reported in pmol $\mathrm{m}^{-2} \mathrm{~s}^{-1}$.

Annual variability of sulfur gas fluxes, 2012-2013

Fifteen field outings took place between March 2012 and March 2013 (Table 1). Chamber bases were installed anew for each outing and did not overlap previous measurement plots. On 30 May and 27 November 2012 and 24 January 2013, a single chamber base was installed and 3 flux measurements were collected. For the other 12 outings, only one flux measurement was made at field moisture per outing. The 3 July and 10 March outings took place in a perennial grassland, the rest from annual grassland sites. There was a precipitation event during the January 24 outing when the chamber lid excluded rainfall from the plot, causing the plot soil to have an average VWC $11 \%$ less than adjacent soil that was not shielded from the rain.

In the dry season, (26 June, 28 June, and 3 July 2012), and 2 outings in the wet season, (27 February and 10 March 2013), 2 separate chamber bases were installed less than $5 \mathrm{~m}$ apart, and one flux measurement was performed at field moisture only from the first plot. These field moisture measurements characterized the annual variation of sulfur gas fluxes and supported the interpretation of soil moisture manipulation experiments.

Two approaches were used to quantify the potential influence of temperature and soil moisture on COS and DMS fluxes. A least squares linear regression was first used to assess the relationship between environmental variables and trace gas fluxes. For DMS flux observations, a more complicated trace gas exchange model was used, developed in Behrendt et al. (2014) for nitrogen gas fluxes. The approach accounts for an optimum soil moisture for trace gas exchange. The model was fitted to the data using a least squares regression technique.

Rainfall manipulations, 2012-2013

From June 2012 to March 2013, 10 outings incorporated the addition of simulated rainfall (Table 1). After collecting air samples for a flux measurement at field conditions, $0.7 \mathrm{~L}$ of water was added to the plot using a piston-pressurized hand water sprayer. This addition is equivalent to $4 \mathrm{~mm}$ rain from a wet season storm typical for the area. Then 2 or 3 subsequent flux measurements were performed with the elevated soil moisture condition.

A single chamber base was installed for the outings on 26 July, 24 August, 20 September, 28 October 2012, and 4 March 2013 to investigate temporal variation from individual plots before and after artificial rainfall addition. For the remaining outings, 2 plots were selected $5 \mathrm{~m}$ apart. A single flux measurement was performed at field moisture from the first plot. After the addition of simulated rainfall to both plots, 2 wetted-condition flux measurements were performed for the first plot and 1 wettedcondition flux measurement for the second plot. Environmental Relative Uptake ratios (ERU) were calculated for individual plots, where ERU $=\left(\mathrm{F}_{\mathrm{COS}} /\right.$ $[\mathrm{COS}]) /\left(\mathrm{F}_{\mathrm{CO} 2} /\left[\mathrm{CO}_{2}\right]\right) . \mathrm{F}_{\mathrm{COS}}$ and $\mathrm{F}_{\mathrm{CO} 2}$ are the observed fluxes of $\mathrm{COS}$ and $\mathrm{CO}_{2}$ respectively, and [COS] and $\left[\mathrm{CO}_{2}\right]$ are the mole ratio of $\mathrm{COS}$ and $\mathrm{CO}_{2}$.

Light/dark chamber experiments, 2014

Because COS uptake occurs through plant stomata, we investigated the influence of using an opaque chamber in measuring COS flux in an outing on 13 March 2014. Four pairs of consecutive light/dark experiments were conducted at the annual grassland site. For dark measurements, the insulating cover remained in place over the chamber lid and air samples were collected according to the protocol described above. For light measurements, the insulating cover was removed and a small external pump circulated ice water through an 
internal PTFE coil, affixed to the sides of the lid with a solid PFA bracket. This internal cooling system was necessary to maintain air temperatures in the light chamber experiments in the same range as the dark chamber experiments. Since only $\mathrm{COS}$ and $\mathrm{CO}_{2}$ were being explored in the 13 March 2014 outing, whole air samples were collected in conditioned SilcoCans with older coatings that were inappropriate for DMS sampling.

\section{Results}

Annual variability of sulfur gas fluxes, 2012-2013

With few exceptions, fluxes of DMS and COS from grasslands at field moisture were of similar magnitude and opposite sign: DMS fluxes ranged from $+39 \mathrm{pmol} \mathrm{m}^{-2} \mathrm{~s}^{-1}$ to slight uptake of $-2 \mathrm{pmol} \mathrm{m}^{-2}$ $\mathrm{s}^{-1}$ and COS fluxes exhibited a maximum uptake of $-75 \mathrm{pmol} \mathrm{m}^{-2} \mathrm{~s}^{-1}$ to emissions at $+7 \mathrm{pmol} \mathrm{m}^{-2} \mathrm{~s}^{-1}$.

In the wet growing season, COS was taken up $\left(-26 \pm 27\right.$ pmol $\left.\mathrm{m}^{-2} \mathrm{~s}^{-1}\right)$ and DMS was emitted to the atmosphere $\left(5.9 \pm 8 \mathrm{pmol} \mathrm{m}^{-2} \mathrm{~s}^{-1}\right)$. During the dry season, uptake of COS was smaller and less variable $\left(-6.1 \pm 10 \mathrm{pmol} \mathrm{m}^{-2} \mathrm{~s}^{-1}\right)$ and production of DMS was reduced $\left(4.2 \pm 4.5 \mathrm{pmol} \mathrm{m}^{-2} \mathrm{~s}^{-1}\right.$, excluding the high late season emission point), with a few instances of DMS uptake and COS production (Fig. 1a, b). Of the 24 flux measurements made at field soil moisture, the 18 chamber experiments reported here yielded $\mathrm{r}^{2}>0.9$ when the flux calculation model was applied to concentrations of DMS and COS over time. Measurements of DMS uptake were limited by the ambient concentration of DMS, which was often below the detection limit of 120 ppt despite the coastal setting. $\mathrm{H}_{2} \mathrm{~S}$ and dimethyl disulfide (DMDS) were also measured, but were present in such low concentrations that no flux measurements could be reported. Two chamber measurements taken in November 2012 resulted in small $\mathrm{CS}_{2}$ sources, both $0.14 \mathrm{pmol} \mathrm{m}^{-2}$ $\mathrm{s}^{-1}$. All other chambers had $\mathrm{CS}_{2}$ mixing ratios below the detection limit.

When divided into wet and dry season observations, COS fluxes had a moderate linear relationship with chamber temperature (Fig. 4) and DMS fluxes had a weak linear relationship to soil moisture in the growing season (Fig. 5). When data from both seasons was taken together, there appeared to be a soil
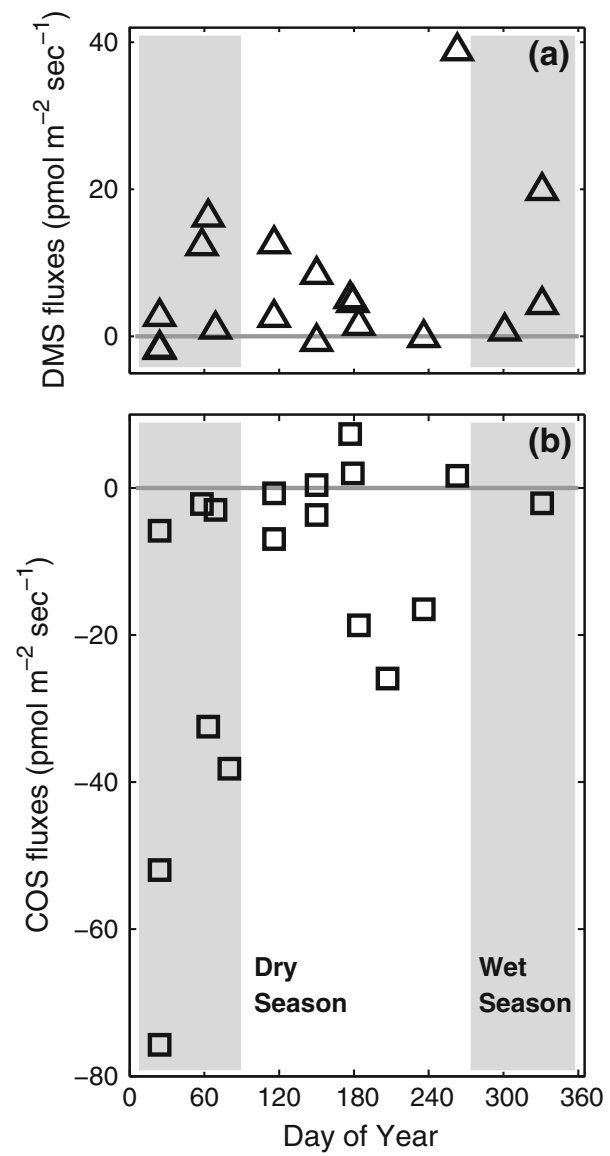

Fig. 1 Natural fluxes of COS and DMS from grassland plots measured monthly; field soil moisture in the dry season varied from 2.2 to $4.8 \%$ VWC, the wet season varied between 13.4 and $25.6 \%$ VWC; air temperature averaged over the course of each flux measurement ranged from 11.7 to $30.0^{\circ} \mathrm{C}$

moisture optimum for DMS production. A coefficient of determination of 0.55 was generated using a least squares approach to fit DMS fluxes to soil moisture observations using equations from Behrendt et al. (2014) (Fig. 5).

Rainfall manipulation, 2012-2013

Adding water to chamber plots in the dry season, when plant matter was dormant or senescing, resulted in a reduction of COS uptake and/or an increase of COS production by the soil and litter system. In contrast, during wet season manipulation experiments with green plants, COS uptake increased significantly (Fig. 2a,b). 
In most cases, artificial rain on plots in both seasons resulted in an increase of net DMS and $\mathrm{CO}_{2}$ release to the atmosphere, usually increasing within $2 \mathrm{~min}$ of adding water and decreasing within $2 \mathrm{~h}$. A notable exception is the September outing (gray upright triangles, Fig. 2c,e): not only did DMS net emissions start out high and then decrease, but $\mathrm{CO}_{2}$ emissions exhibited an increase over the next $2 \mathrm{~h}$. In the 4 March 2013 outing (upright triangles, Fig. 2d), a site $2 \mathrm{~m}$ from the 27 February 2013 outing (black circles), $\mathrm{CO}_{2}$ fluxes started high relative to previous measurements at $24.7 \mu \mathrm{mol} \mathrm{m}{ }^{-2} \mathrm{~s}^{-1}$, then emission decreased after water addition.

Of the 12 total instances when chamber $\mathrm{CS}_{2}$ mixing ratios were above the detection limit, only one chamber measurement in September yielded a flux greater than $1 \mathrm{pmol} \mathrm{m}^{-2} \mathrm{~s}^{-1}$, at $18 \mathrm{pmol} \mathrm{m}^{-2} \mathrm{~s}^{-1}$ (Table 2). Otherwise, $\mathrm{CS}_{2}$ fluxes were constrained between -0.8 to $0.2 \mathrm{pmol} \mathrm{m}^{-2} \mathrm{~s}^{-1}$. 10 of these fluxes occurred after soil water was amended, otherwise no clear relationship was found between $\mathrm{CS}_{2}$ fluxes and the variables measured.

\section{Light/dark chamber experiments, 2014}

COS fluxes over a single plot taken with a dark and light chamber lid yielded similar results, averaging $-5.8 \pm 3.4$ and $-7.9 \pm 3.3 \mathrm{pmol} \operatorname{COS} \mathrm{m}^{-2} \mathrm{~s}^{-1}$, respectively, over the course of several hours (Fig. 3a). In contrast, $\mathrm{CO}_{2}$ fluxes from dark chambers had remarkably less variability $\left(4.5 \pm 0.05 \mu \mathrm{mol} \mathrm{CO}_{2} \mathrm{~m}^{-2} \mathrm{~s}^{-1}\right)$ than compared to measurements made under light conditions $\left(3.6 \pm 3.9 \mu \mathrm{mol} \mathrm{CO} \mathrm{m}^{-2} \mathrm{~s}^{-1}\right)$ (Fig. 3b).

\section{Discussion}

Here we have demonstrated an approach for measuring ecosystem fluxes of reduced sulfur gases over a broad range of soil moistures and temperatures, with
Fig. $2 \mathrm{COS}, \mathrm{CO}_{2}$, and DMS fluxes from in situ grassland plots before and after water additions: gray symbols are fluxes from a perennial grassland site and black symbols represent fluxes from annual grassland sites; data is shown for measurements where flux calculation yielded $\mathrm{r}^{2}>0.9$ for 3 or more time points in the experiment
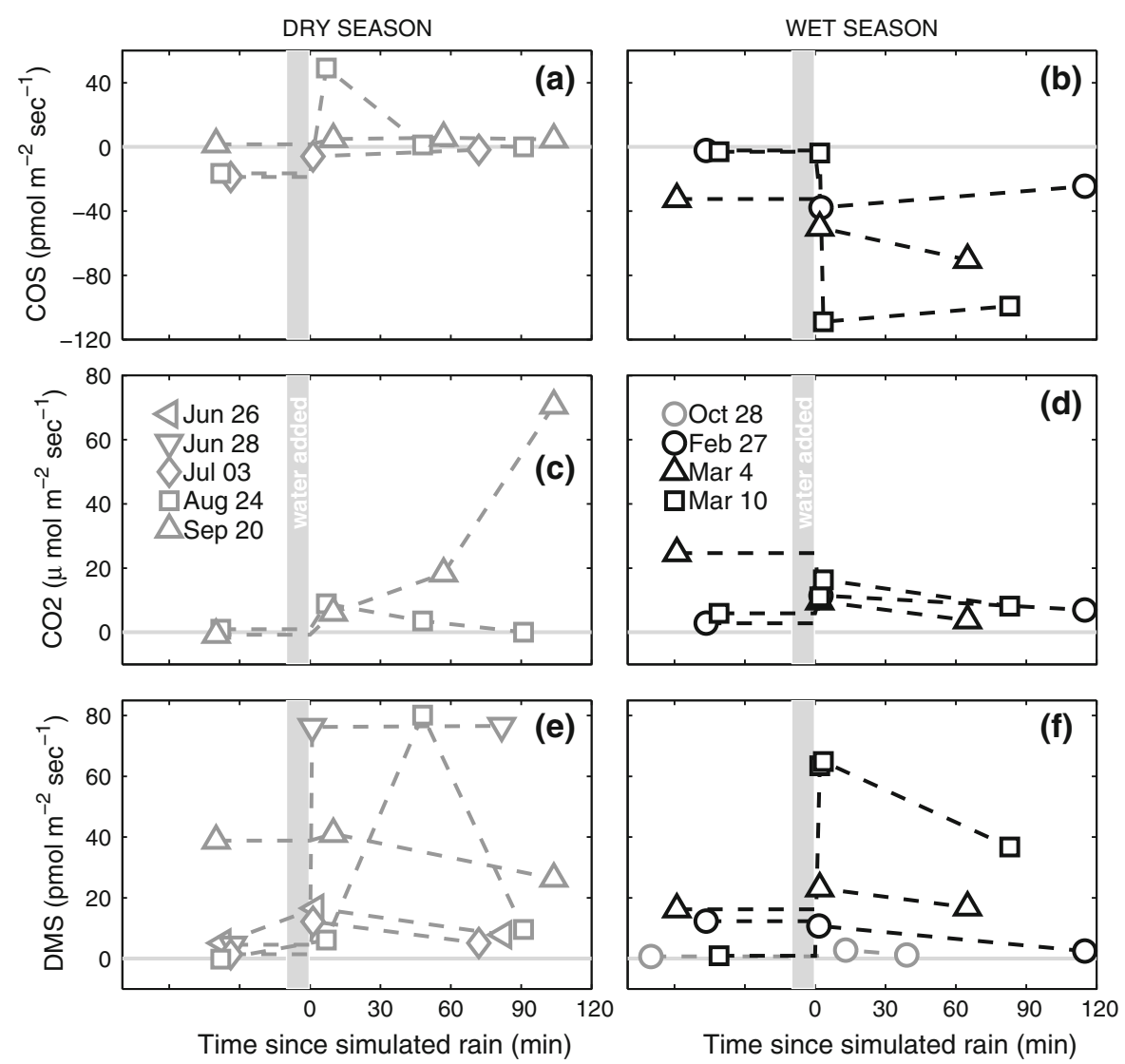
Table 2 Range of DMS and $\mathrm{CS}_{2}$ fluxes reported in the literature converted to pmol $\mathrm{m}^{-2} \mathrm{~s}^{-1}$ and compared to this study

\begin{tabular}{lll}
\hline Citation & Ecosystem & DMS pmol m $\mathrm{s}^{-1}$ \\
\hline Geng and Mu (2004) & Grass lawn & 0 to 3 \\
de Mello and Hines (1994) & Sphagnum peatlands & 1 to 118 \\
DeLaune et al. (2002) & Coastal marsh & 12 to 1247 \\
This study & Coastal grassland & $\sim 0$ to 67 \\
\hline Citation & Ecosystem & $\mathrm{CS}_{2} \mathrm{pmol} \mathrm{m}^{-2} \mathrm{~s}^{-1}$ \\
\hline Steinbacher et al. (2004) & Temperate spruce forest & -0.11 to 0.23 \\
Melillo and Steudler (1989) & Temperate coniferous forest & 0.3 to 4 \\
DeLaune et al. (2002) & Coastal marsh & 6 to 625 \\
This study & Coastal grassland & -0.8 to 18 \\
\hline
\end{tabular}

special attention to the large swings in fluxes that occur after soil moisture change, or artificial rainfall events. In a mediterranean grassland, this determination was straightforward because the landscape had few green plants during the dry season, allowing for DMS and COS fluxes to be quantified without the complication of possible plant/live root DMS production reported for other grasses (Kanda et al. 1995) and the well known COS uptake through plant stomata (Seibt et al. 2010; Stimler et al. 2010).

DMS, $\mathrm{CO}_{2}$, and soil moisture

The field moisture flux measurements indicate DMS production was coincident with an optimum soil

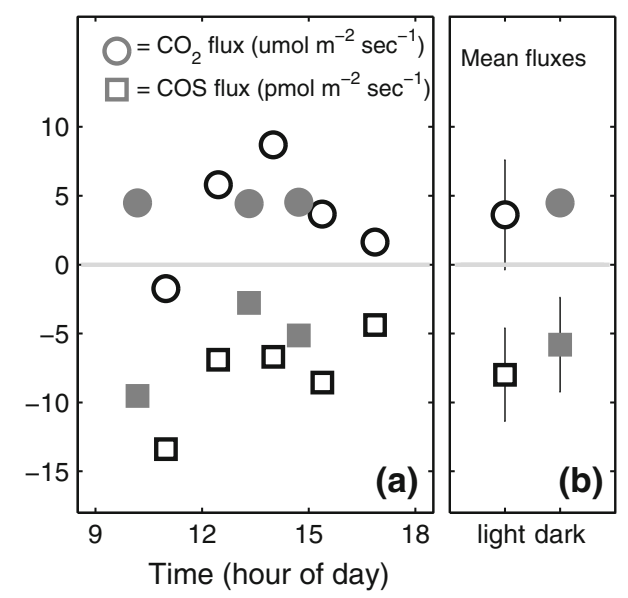

Fig. 3 In situ measurements of $\mathrm{CO}_{2}$ and $\mathrm{COS}$ from a single plot using a static incubation chamber with an insulating cover to block out light (filled symbols) or with the cover removed (unfilled symbols) on 13 March 2014; the left panel shows how fluxes varied by time of day and the right panel shows the mean of all measurements, error bars representing one standard deviation moisture content and the presence of living grasses (Fig. 5). Adapting the approach of a recent study by Jardine et al. (2015), we fit an equation developed for NO soil fluxes (Behrendt et al. 2014) to our field data, yielding a coefficient of determination of 0.55 . Both this study and Jardine et al. (2015) found that soil DMS production had an optimum soil moisture content where emissions were maximum, trending towards 0 for very dry and very wet soils. This is consistent with generally low DMS emissions from dead grass and dry soil during the bulk of the dry season, followed by an inverse relationship with soil moisture during the dry season. DMS emissions to the atmosphere were on average higher during the wet season, when field soil moisture had a much stronger influence on DMS production compared to dry season fluxes (Fig. 5). The DMS fluxes here fall within the expected range found in the small number of previous field measurements (Table 2).

The soil moisture manipulation experiments show that increasing soil water content stimulated DMS fluxes to the atmosphere in the 6 of 9 cases where DMS fluxes at field moisture were initially near zero (Fig. 2). Wet season plots yielded much larger increases in DMS production after water addition, perhaps from an already active microbial population and from interactions with live plants. DMS production has been found previously over several important agricultural grasses (Kanda et al. 1995). In soils, DMS emissions are thought to be microbially-mediated by DMSO respiration or by degradation of amino acids and other biological compounds (Schäfer et al. 2010). However, observations of $\mathrm{CO}_{2}$ do not reveal a simple link between microbial activity and terrestrial DMS production. Basal respiration, observing the $\mathrm{CO}_{2}$ flux from soil, is a well-established method for measuring 
soil microbial activity; however, this does not take into account facultative microbes that can use multiple substrates to support metabolism.

Soils that experience lengthy dry periods have been found to exhibit increases in carbon mineralization after rain events due to a combination of released soil organic matter and increased microbial activity (Fierer and Schimel 2003; Jarvis et al. 2007, Unger et al. 2010). This effect was observed in the 20 September 2012 outing, when a sustained increase in $\mathrm{CO}_{2}$ net release to the atmosphere was observed over the course of $2 \mathrm{~h}$. In this outing, DMS production was already high and was suppressed slightly by the water addition. Only one plot on 28 June saw a persistent order of magnitude increase of DMS emissions (Fig. 2e).

\section{Relative importance of terrestrial DMS fluxes}

While DMS is typically associated with marine ecosystems, terrestrial ecosystems contribute significantly through a different set of mechanisms (Schäfer et al. 2010). In situ DMS fluxes observed over the course of this study ranged from +39 to -2 pmol DMS $\mathrm{m}^{-2} \mathrm{~s}^{-1}$, with artificially wetted plots having generally higher fluxes from near 0 to +80 pmol DMS $\mathrm{m}^{-2} \mathrm{~s}^{-1}$. We can roughly estimate the relative importance of terrestrial DMS emissions compared to recent estimates of global oceanic DMS emissions: $28 \mathrm{Tg} \mathrm{S} \mathrm{a}^{-1}$ (Lana et al. 2011). To compare this ocean estimate to our study, we divide by $3.619 \times 10^{14} \mathrm{~m}^{2}$ ocean area, $3.154 \times 10^{7} \mathrm{~s} \mathrm{a}^{-1}, 32.065 \times 10^{-24} \mathrm{Tg} \mathrm{S}$ pmol $\mathrm{S}^{-1}$, and 1 pmol DMS pmol $\mathrm{S}^{-1}$, yielding $77 \mathrm{pmol}$ DMS m $\mathrm{m}^{-2} \mathrm{~s}^{-1}$. This ocean estimate is of the same order of magnitude as many of the wet season DMS flux observations presented in this study. While this scaling is purposefully simple, masking the heterogeneity of DMS fluxes and the much greater area of the ocean systems, aerobic terrestrial DMS emissions are nonetheless a portion of the sulfur budget that needs to be considered to assemble a complete biogeochemical cycle.

Seasonal COS fluxes and temperature

Living plants are the largest sink of COS in the troposphere (Protoschill-Krebs and Kesselmeier 1992; Watts 2000; Montzka et al. 2007; Campbell et al. 2008). At the field sites during the dry season, grass dries out and organic matter senesces in place, temporarily diminishing the dominant COS sink. In the wet season, new growth sprouts through the enduring dense litter layer. In the dry season, temperature appeared to have had a greater influence on COS exchange (Fig. 3). Taken together with soil VWC, a multiple linear regression of temperature and moisture on COS exchange yielded an $r^{2}$ of $0.67(n=8)$. After plant growth began again in the wet season, the relationship to temperature became more complicated (Fig. 4), depending more on whether living grasses were present. The relationship of COS fluxes to soil conditions may be based on physical constraints to soil/litter-atmosphere trace gas exchange and the availability of COS precursors.

Soil structure and water content are additional factors regulating atmospheric COS uptake. In a study of 4 soil types, the uptake of COS was controlled by the diffusivity of the soil as related to water-filled pore space (Van Diest and Kesselmeier 2008). For this particular soil, COS uptake could be hindered by decreased diffusivity, preventing COS from entering into the soil profile where it was consumed or adsorbed. When water was added to dry season plots, uptake appeared to decrease in all cases (Fig. 2a); however, it is impossible to separate COS uptake from production without using an additional tracer method (Fig. 5).

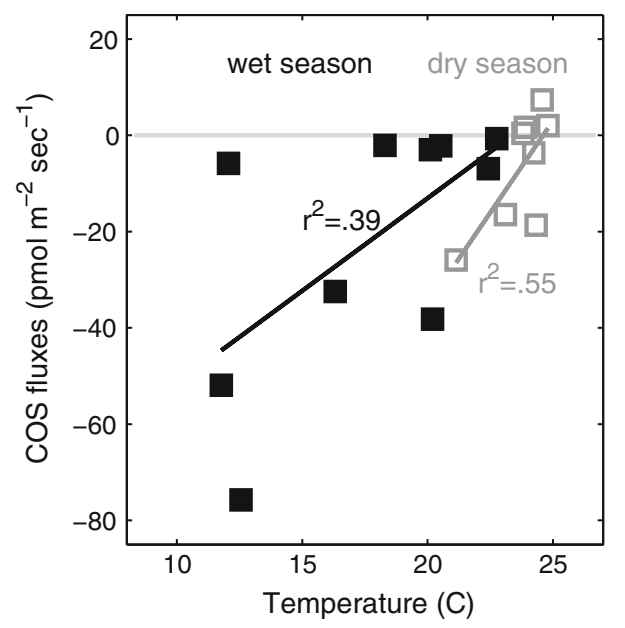

Fig. 4 Fluxes of COS and average chamber temperature. Black-filled symbols are wet season measurements; gray symbols are dry season measurements; the $\mathrm{r}^{2}$ values given are for least squares linear regression 
Sulfur-containing amino acids can act as the precursors of COS (Minami and Fukushi 1981) and microbes can actively produce COS through oxidation of other organic compounds (Kelly and Baker 1990). It may be expected that COS production should increase with soil moisture, as increased microbial activity may liberate more organic matter. After wetting a plot during the 24 August 2012 outing, apparent production far exceeded COS uptake from the atmosphere (Fig. 2a). On the other hand, this could have been the result of displacing the soil atmosphere by the addition of water, leading to emission of COS otherwise trapped in the soil profile. This second interpretation is supported by a subsequent, much lower observation $41 \mathrm{~min}$ later. This suggests that an increase in COS production caused by a change in available water may be initially dampened by the increase in water-filled pore space, acting as a barrier between in-soil production of COS and the atmosphere.

\section{Growing season COS net uptake}

Most of the ecosystem exchange of carbon in a mediterranean grassland happens during the wet, growing season (Xu and Baldocchi 2004). Not surprisingly, in this study the grassland took up COS during the wet season when plants were green and

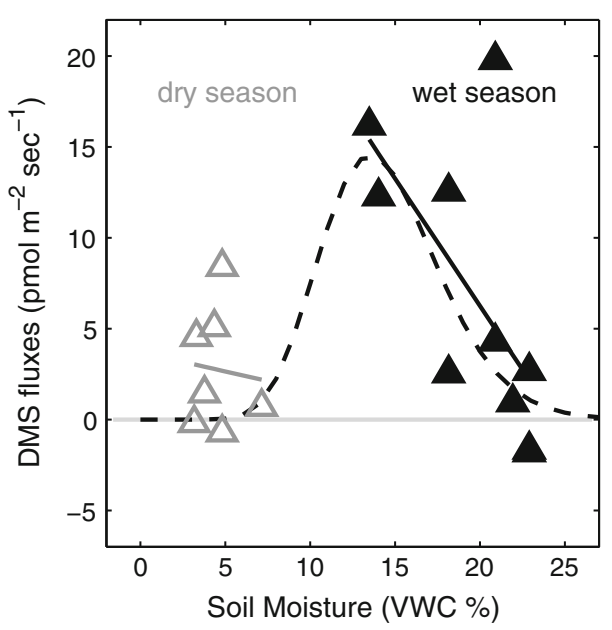

Fig. 5 Field (unmanipulated) soil moisture and DMS fluxes in the dry season (gray triangles) and the wet season (black triangles); the $\mathrm{r}^{2}$ is 0.41 for a least squares linear regression of VWC and DMS fluxes for the wet season only, and 0.55 for the model adapted Behrendt et al. (2014) regressed on the whole data set photosynthetic rates were high (Figs. 1b, 2b, 3a,b). Using light and dark chambers alternately on the same plot, we found COS fluxes in light and dark chambers did not vary significantly, whereas $\mathrm{CO}_{2}$ fluxes were much less variable when measured with dark chambers (Fig. 3a,b). There are two explanations for the net $\mathrm{CO}_{2}$ production during most of the light chamber experiments. The first is that in 2014, this area of California was in a severe drought; it is not surprising to have a grassland switch between a net source and sink of $\mathrm{CO}_{2}$ to the atmosphere depending on soil temperature and water status (Ma et al. 2007). The second is that despite mixing the chamber air with a fan and incorporating a water-cooled coil within the chamber lid body, exposing the plot to light will still cause temperature differences within the chamber soil and variations in respiration.

Uptake of COS by plants is thought to occur by diffusion into stomata followed by a reaction that does not depend on light. Stomata do not necessary close quickly or completely in dark conditions (Manzoni et al. 2011; Vico et al. 2011). As long as the stomata are open, $\operatorname{COS}$ can diffuse into the plant leaf and react with carbonic anhydrase, where it is irreversibly destroyed. For dark $\mathrm{CO}_{2}$ flux measurements, if no $\mathrm{CO}_{2}$ is being consumed by the leaf photosystems, there is little concentration gradient to drive the flux of $\mathrm{CO}_{2}$ into the $\mathrm{C} 3$ leaf even when stomata are open.

Under medium and high light conditions, COS and $\mathrm{CO}_{2}$ are taken up in leaves at a fairly consistent ratio relative to their ambient concentrations, known as the leaf relative uptake (LRU) (Campbell et al. 2008; Stimler et al. 2011). Measurements of carbonyl sulfide have recently been used as a tracer for gross primary production (GPP) (Asaf et al. 2013; Billesbach et al. 2014), relying on LRU estimates (Sandoval-Soto et al. 2005; Campbell et al. 2008; Hilton et al. 2015). Soil fluxes need to be known to allocate ecosystem-level COS fluxes into leaf- and soil-oriented exchanges. To assess the contribution of the fluxes observed in the absence of photosynthesizing plants on ecosystem COS exchange during the wet season, we used the relative ratio of $\mathrm{COS}$ and $\mathrm{CO}_{2}$ fluxes normalized to their respective ambient concentrations or ERU (Fig. 6).

Soil COS flux observations are generally low compared to leaf-level uptake: observations of temperate and subtropical forest COS soil fluxes range between -8 and +1.45 pmol COS $\mathrm{m}^{-2} \mathrm{~s}^{-1}$ (Castro 
and Galloway 1991; Steinbacher et al. 2004; Yi et al. 2007; White et al. 2010). Compared to ecosystem scale forest measurements (Xu et al. 2002), the soil term represents $8 \%$ of the total COS exchange. However, recent measurements have demonstrated that agricultural soils emit substantially more COS (Maseyk et al. 2014; Whelan et al. 2016).

With artificial rain events, we assessed how ecosystem or soil relative uptake (ERU or SRU) changes over senescent grassland plots with increased soil moisture (Fig. 6). In grassland plots without green plants, SRU returned to near the initial value within $2 \mathrm{~h}$ of water addition. This suggests that the soil system SRU exhibited resilience and readily recovered from recent changes in soil moisture. In contrast, growing season plots with green plants showed a large deviation from the initial ERU (Fig. 6). The ERU of our unmanipulated grassland plots had similar variability to 2 days of high frequency soil measurements in a senescing grassland in Colorado (Berkelhammer et al. 2014) (Fig. 7). The potential for large changes in flux patterns after precipitation as in Fig. 2 indicates a dire need for more study of this phenomenon.

\section{Conclusions}

DMS emissions are an important component of the global sulfur cycle, moving sulfur that was weathered from continents back to terrestrial ecosystems through the atmosphere. To our knowledge, this study is the first reported instance of a pulse of DMS emissions in oxic soils after a precipitation event, artificial or otherwise. This phenomenon may have a relationship to the Birch effect, where wetting dry soils causes a large but ephemeral increase in soil respiration. Further studies into these types of carbon mineralization events can help clarify possible links between significant fluxes in the carbon and sulfur cycles.

The COS observations in this study will help constrain the potential influence of soil trace gas exchange on large scale GPP estimates (Whelan et al. 2016). The advantage of estimating GPP with COS lies in generating a real-time, daylight proxy for GPP, contrasted with annual estimates of NPP by harvesting whole plants or problems with using eddy flux covariance towers to measure ecosystem respiration at night when turbulent mixing is low (Hilton et al.

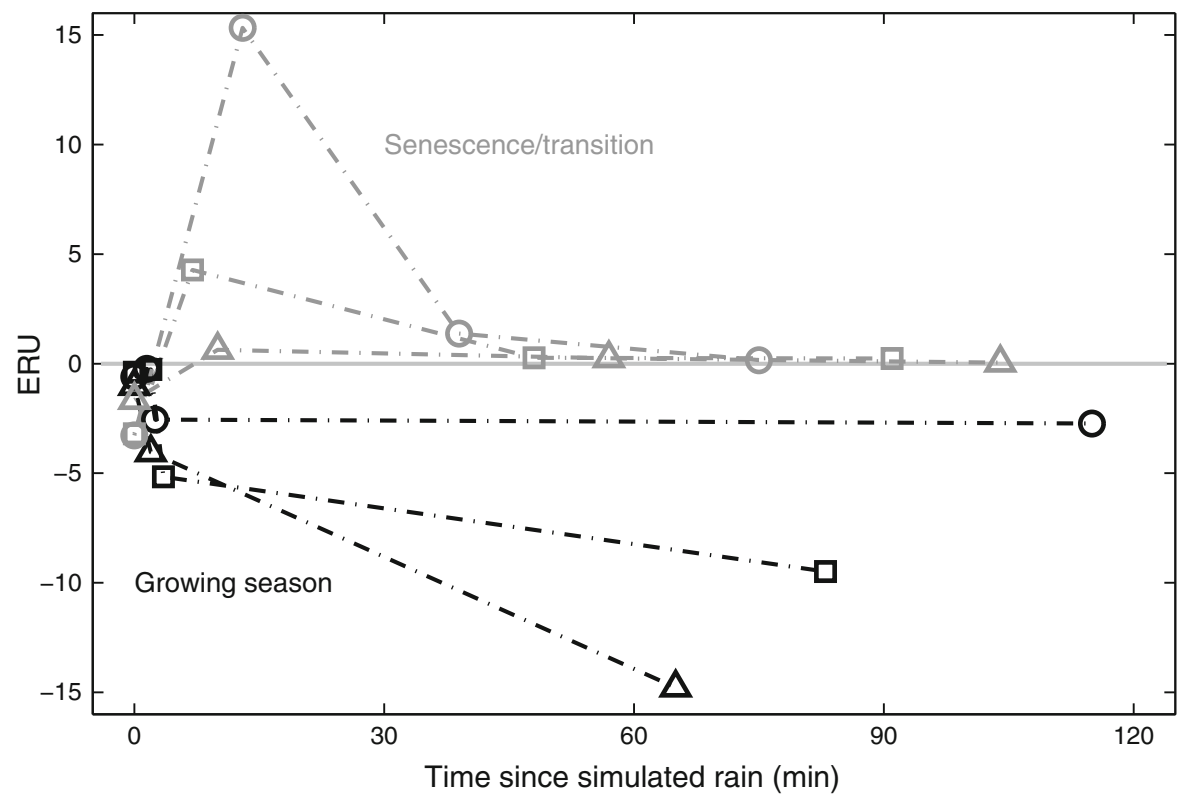

Fig. 6 Ecosystem relative uptake (ERU) after simulated rainfall: gray symbols are from plots in senescence or transition into the wet season. These values could be considered to represent a soil relative uptake (SRU) because few green plants are present. The black symbols are for experiments performed over plots of living grasses. The symbols here correspond to the legend in Fig. 2 


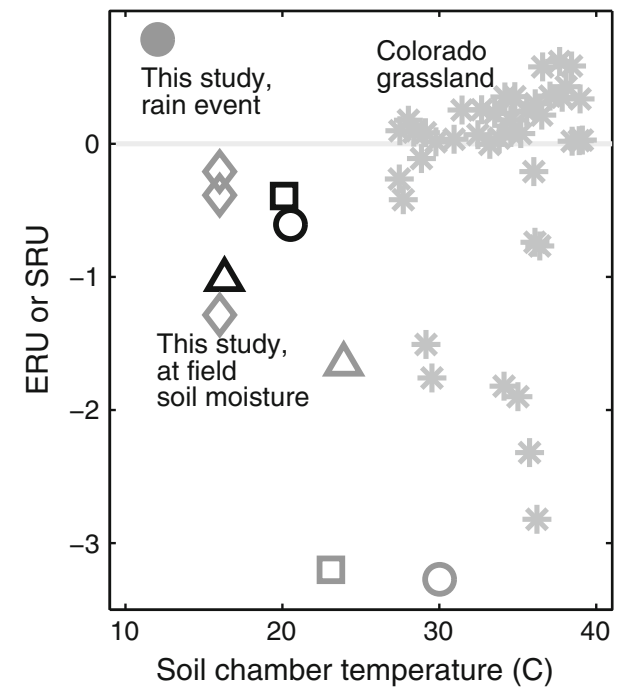

Fig. 7 Ecosystem relative uptake (ERU) of unmanipulated plots at field soil moisture, compared to the soil relative uptake (SRU) of a Colorado grassland in senescence (Berkelhammer et al. 2014), in gray asterisks. The field outing in January 24, 2013 took place during a rainstorm, represented by a filled circle; the other symbols correspond to the legend in Fig. 2

2015). This technique may be relevant to future studies focused on carbon sequestration efforts, assessing the effects of drought stress, and large-scale manipulation experiments where high frequency GPP estimates are needed. Taking soil COS fluxes into account when applying this method will support more accurate carbon cycle characterization.

Recently, Jardine et al. (2015) have used a PTR-MS to measure DMS in near real time and quantum cascade lasers capable of measuring COS have become commercially available. Laser-based and other quick-MS methods will create new possibilities for measuring these important fluxes in real time. Unfortunately, only a few people have installed these instruments in mobile laboratories. The future for these questions will rely on installing instruments quasi-permanently in field conditions. We have demonstrated a straightforward way of making reduced sulfur gas flux observations in a remote location, where samples need to be transported back to a laboratory. This expands the spatial extent of potential measurements considerably.

Acknowledgments We thank the California State Parks Service for site access; J. Chalfant, M. Schulz, C. Lawrence, J. Rhim, L. Ledesma, J. Kim, K. Barnash, J.E. Campbell, and T.
Bhattacharya for field assistance; C. Lewis for suggestions on experimental design; W. Silver for sample processing support; M. Berkelhammer for data sharing; J. Mühle and R. Weiss for standard calibration; and A. Goldstein, R. Amundsen, E. Brzostek, and 2 anonymous reviewers for manuscript feedback. This work was supported by the Martin Foundation, the NSF-EAR Grant Number 0819972, and NSF-AGS Grant Number 1433257. Data presented in this work can be found in the UC3 archival system Merritt data repository.

Open Access This article is distributed under the terms of the Creative Commons Attribution 4.0 International License (http:// creativecommons.org/licenses/by/4.0/), which permits unrestricted use, distribution, and reproduction in any medium, provided you give appropriate credit to the original author(s) and the source, provide a link to the Creative Commons license, and indicate if changes were made.

\section{References}

Alcolombri U, Ben-Dor S, Feldmesser E et al (2015) Identification of the algal dimethyl sulfide-releasing enzyme: a missing link in the marine sulfur cycle. Science 348:1466-1469. doi:10.1126/science.aab1586

Andreae MO (1990) Ocean-atmosphere interactions in the global biogeochemical sulfur cycle. Mar Chem 30:1-29. doi:10.1016/0304-4203(90)90059-L

Andreae MO, Crutzen PJ (1997) Atmospheric aerosols: biogeochemical sources and role in atmospheric chemistry. Science 276:1052-1058. doi:10.1126/science.276.5315. 1052

Asaf D, Rotenberg E, Tatarinov F et al (2013) Ecosystem photosynthesis inferred from measurements of carbonyl sulphide flux. Nat Geosci 6:186-190. doi:10.1038/ ngeo1730

Behrendt T, Veres PR, Ashuri F et al (2014) Characterisation of NO production and consumption: new insights by an improved laboratory dynamic chamber technique. Biogeosciences 11:5463-5492. doi:10.5194/bg-11-5463-2014

Berkelhammer M, Asaf D, Still C et al (2014) Constraining surface carbon fluxes using in situ measurements of carbonyl sulfide and carbon dioxide. Global Biogeochem Cycles 28:161-179. doi:10.1002/2013GB004644

Billesbach DP, Berry JA, Seibt U et al (2014) Growing season eddy covariance measurements of carbonyl sulfide and $\mathrm{CO}_{2}$ fluxes: $\mathrm{COS}$ and $\mathrm{CO}_{2}$ relationships in Southern Great Plains winter wheat. Agric For Meteorol 184:48-55. doi:10.1016/j.agrformet.2013.06.007

Birch HF (1958) The effect of soil drying on humus decomposition and nitrogen availability. Plant Soil 10:9-31. doi:10. 1007/BF01343734

Brühl C, Lelieveld J, Crutzen PJ, Tost H (2012) The role of carbonyl sulphide as a source of stratospheric sulphate aerosol and its impact on climate. Atmos Chem Phys 12:1239-1253. doi:10.5194/acp-12-1239-2012

Campbell JE, Carmichael GR, Chai T et al (2008) Photosynthetic control of atmospheric carbonyl sulfide during the 
growing season. Science 322:1085-1088. doi:10.1126/ science. 1164015

Campbell JE, Whelan ME, Seibt U et al (2015) Atmospheric carbonyl sulfide sources from anthropogenic activity: implications for carbon cycle constraints. Geophys Res Lett 42(8):3004-3010. doi:10.1002/2015GL063445

Castro MS, Galloway JN (1991) A comparison of sulfur-free and ambient air enclosure techniques for measuring the exchange of reduced sulfur gases between soils and the atmosphere. J Geophys Res 96:15427-15437

Charlson RJ, Warren SG, Lovelock JE, Andreae MO (1987) Oceanic phytoplankton, atmospheric sulphur, cloud albedo and climate. Nature 326:655-661

Cooper DJ, Saltzman ES (1987) Uptake of carbonyl sulfide by silver nitrate impregnated filters: Implications for the measurement of low level atmospheric $\mathrm{H}_{2} \mathrm{~S}$. Geophys Res Lett 14:206-209. doi:10.1029/GL014i003p00206

de Mello WZ, Hines ME (1994) Application of static and dynamic enclosures for determining dimethyl sulfide and carbonyl sulfide exchange in Sphagnum peatlands: implications for the magnitude and direction of flux. J Geophys Res 99:14601-14607

DeLaune RD, Devai I, Lindau CW (2002) Flux of reduced sulfur gases along a salinity gradient in Louisiana coastal marshes. Estuarine Coastal Shelf Sci 54:1003-1011

Devai I, DeLaune RD (1995) Formation of volatile sulfur compounds in salt marsh sediment as influenced by soil redox condition. Org Geochem 23:283-287. doi:10.1016/ 0146-6380(95)00024-9

Fall R, Albritton DL, Fehsenfeld FC et al (1988) Laboratory studies of some environmental variables controlling sulfur emissions from plants. J Atmos Chem 6:341-362. doi:10. 1007/BF00051596

Fierer N, Schimel JP (2003) A proposed mechanism for the pulse in carbon dioxide production commonly observed following the rapid rewetting of a dry soil. Soil Sci Soc Am J 67:798-805

Geng C, Mu Y (2004) Carbonyl sulfide and dimethyl sulfide exchange between lawn and the atmosphere. J Geophys Res D: Atmos 109:D12302. doi:10.1029/2003JD004492

Geng C, Mu Y (2006) Carbonyl sulfide and dimethyl sulfide exchange between trees and the atmosphere. Atmos Environ 40:1373-1383. doi:10.1016/j.atmosenv.2005.10. 023

Hilton TW, Zumkehr A, Kulkarni S et al (2015) Large variability in ecosystem models explains uncertainty in a critical parameter for quantifying GPP with carbonyl sulphide. Tellus B. doi:10.3402/tellusb.v67.26329

Jardine K, Yañez-Serrano AM, Williams J et al (2015) Dimethyl sulfide in the Amazon rain forest. Global Biogeochem Cycles 29:2014GB004969. doi:10.1002/2014GB004969

Jarvis P, Rey A, Petsikos C et al (2007) Drying and wetting of Mediterranean soils stimulates decomposition and carbon dioxide emission: the "Birch effect". Tree Physiol 27:929-940. doi:10.1093/treephys/27.7.929

Kanda K, Tsuruta H, Minami K (1995) Emissions of biogenic sulfur gases from maize and wheat fields. Soil Sci Plant Nutr 41:1-8. doi:10.1080/00380768.1995.10419553

Kelly DP, Baker SC (1990) The organosulphur cycle: aerobic and anaerobic processes leading to turnover of $\mathrm{C} 1$-sulphur compounds. FEMS Microbiol Rev 7:241-246. doi:10. 1111/j.1574-6968.1990.tb04919.x

Kesselmeier J, Teusch N, Kuhn U (1999) Controlling variables for the uptake of atmospheric carbonyl sulfide by soil. J Geophys Res 104:11577-11584. doi:10.1029/ 1999JD900090

Khan MAH, Whelan ME, Rhew RC (2012) Analysis of low concentration reduced sulfur compounds (RSCs) in air: storage issues and measurement by gas chromatography with sulfur chemiluminescence detection. Talanta 88:581-586. doi:10.1016/j.talanta.2011.11.038

Lana A, Bell TG, Simó R et al (2011) An updated climatology of surface dimethlysulfide concentrations and emission fluxes in the global ocean. Global Biogeochem Cycles 25:GB1004. doi:10.1029/2010GB003850

Li C-Y, Wei T-D, Zhang S-H et al (2014) Molecular insight into bacterial cleavage of oceanic dimethylsulfoniopropionate into dimethyl sulfide. PNAS 111:1026-1031. doi:10.1073/ pnas. 1312354111

Livingston GP, Hutchinson GL (1995) Enclosure-based measurement of trace gas exchange: applications and sources of error. In: Biogenic trace gases: measuring emissions from soil and water, pp 14-51

Lomans BP, van der Drift C, Pol A, den Camp HJMO (2002) Microbial cycling of volatile organic sulfur compounds. Cellular Mol Life Sci 59:575-588

Ma S, Baldocchi DD, Xu L, Hehn T (2007) Inter-annual variability in carbon dioxide exchange of an oak/grass savanna and open grassland in California. Agric For Meteorol 147:157-171. doi:10.1016/j.agrformet.2007.07.008

Manzoni S, Vico G, Katul G et al (2011) Optimizing stomatal conductance for maximum carbon gain under water stress: a meta-analysis across plant functional types and climates. Funct Ecol 25:456-467. doi:10.1111/j.1365-2435.2010. 01822.x

Maseyk K, Berry JA, Billesbach D et al (2014) Sources and sinks of carbonyl sulfide in an agricultural field in the Southern Great Plains. PNAS 111:9064-9069. doi:10. 1073/pnas.1319132111

Melillo JM, Steudler PA (1989) The effect of nitrogen fertilization on the $\mathrm{COS}$ and $\mathrm{CS}_{2}$ emissions from temperature forest soils. J Atmos Chem 9:411-417

Minami K, Fukushi S (1981) Volatilization of carbonyl sulfide from paddy soils treated with sulfur-containing substances. Soil Sci Plant Nutr 27:339-345. doi:10.1080/00380768. 1981.10431288

Montzka SA, Calvert P, Hall BD et al (2007) On the global distribution, seasonality, and budget of atmospheric carbonyl sulfide (COS) and some similarities to $\mathrm{CO}_{2}$. J Geophys Res Atmos. doi:10.1029/2006JD007665

Notni J, Schenk S, Protoschill-Krebs G et al (2007) The missing link in COS metabolism: a model study on the reactivation of carbonic anhydrase from its hydrosulfide analogue. ChemBioChem 8:530-536. doi:10.1002/cbic. 200600436

Protoschill-Krebs G, Kesselmeier J (1992) Enzymatic pathways for the consumption of carbonyl sulphide (COS) by higher plants. Botanica Acta 105:206-212

Protoschill-Krebs G, Wilhelm C, Kesselmeier J (1996) Consumption of carbonyl sulphide (COS) by higher plant 
carbonic anhydrase (CA). Atmos Environ 30:3151-3156. doi:10.1016/1352-2310(96)00026-X

Quinn PK, Bates TS (2011) The case against climate regulation via oceanic phytoplankton sulphur emissions. Nature 480:51-56. doi:10.1038/nature10580

Sandoval-Soto L, Stanimirov M, Von Hobe M et al (2005) Global uptake of carbonyl sulfide (COS) by terrestrial vegetation: Estimates corrected by deposition velocities normalized to the uptake of carbon dioxide $\left(\mathrm{CO}_{2}\right)$. Biogeosci 2:125-132. doi:10.5194/bg-2-125-2005

Schäfer H, Myronova N, Boden R (2010) Microbial degradation of dimethylsulphide and related $\mathrm{C} 1$-sulphur compounds: organisms and pathways controlling fluxes of sulphur in the biosphere. J Exp Bot 61:315-334. doi:10.1093/jxb/erp355

Schulz M, Stonestrom D, Von Kiparski G et al (2011) Seasonal dynamics of $\mathrm{CO}_{2}$ profiles across a soil chronosequence, Santa Cruz, California. Appl Geochem 26(Suppl):S132S134. doi:10.1016/j.apgeochem.2011.03.048

Seibt U, Kesselmeier J, Sandoval-Soto L et al (2010) A kinetic analysis of leaf uptake of COS and its relation to transpiration, photosynthesis and carbon isotope fractionation. Biogeosci 7:333-341. doi:10.5194/bg-7-333-2010

Sparling GP, Searle PL (1993) Dimethyl sulphoxide reduction as a sensitive indicator of microbial activity in soil: the relationship with microbial biomass and mineralization of nitrogen and sulphur. Soil Biol Biochem 25:251-256. doi:10.1016/0038-0717(93)90035-A

Steinbacher M, Bingemer HG, Schmidt U (2004) Measurements of the exchange of carbonyl sulfide (OCS) and carbon disulfide $\left(\mathrm{CS}_{2}\right)$ between soil and atmosphere in a spruce forest in central Germany. Atmos Environ 38:6043-6052

Stimler K, Montzka SA, Berry JA et al (2010) Relationships between carbonyl sulfide (COS) and $\mathrm{CO}_{2}$ during leaf gas exchange. N Phytol 186:869-878. doi:10.1111/j.14698137.2010.03218.x

Stimler K, Berry JA, Montzka SA, Yakir D (2011) Association between carbonyl sulfide uptake and $18 \Delta$ during gas exchange in C3 and C4 leaves. Plant Physiol 157:509-517. doi:10.1104/pp.111.176578

Sun W, Maseyk K, Lett C, Seibt U (2016) Litter dominates surface fluxes of carbonyl sulfide in a Californian oak woodland. J Geophys Res Biogeosci 121:2015JG003149. doi:10.1002/2015JG003149

Unger S, Máguas C, Pereira JS et al (2010) The influence of precipitation pulses on soil respiration-assessing the
"Birch effect" by stable carbon isotopes. Soil Biol Biochem 42:1800-1810. doi:10.1016/j.soilbio.2010.06.019

Van Diest H, Kesselmeier J (2008) Soil atmosphere exchange of carbonyl sulfide (COS) regulated by diffusivity depending on water-filled pore space. Biogeosci 5:475-483. doi:10. 5194/bg-5-475-2008

Vico G, Manzoni S, Palmroth S, Katul G (2011) Effects of stomatal delays on the economics of leaf gas exchange under intermittent light regimes. N Phytol 192:640-652. doi:10.1111/j.1469-8137.2011.03847.x

Watts SF (2000) The mass budgets of carbonyl sulfide, dimethyl sulfide, carbon disulfide and hydrogen sulfide. Atmos Environ 34:761-779. doi:10.1016/S1352-2310(99)003428

Whelan M, Rhew R (2015) Carbonyl sulfide produced by abiotic thermal and photo-degradation of soil organic matter from wheat field substrate. J Geophys Res Biogeosci 2014JG002661. doi:10.1002/2014JG002661

Whelan ME, Min D-H, Rhew RC (2013) Salt marshes as a source of atmospheric carbonyl sulfide. Atmos Environ 73:131-137. doi:10.1016/j.atmosenv.2013.02.048

Whelan ME, Hilton TW, Berry JA et al (2016) Carbonyl sulfide exchange in soils for better estimates of ecosystem carbon uptake. Atmos Chem Phys 16:3711-3726. doi:10.5194/ acp-16-3711-2016

White AF, Schulz MS, Vivit DV et al (2008) Chemical weathering of a marine terrace chronosequence, Santa Cruz, California I: Interpreting rates and controls based on soil concentration-depth profiles. Geochim Cosmochim Acta 72:36-68. doi:10.1016/j.gca.2007.08.029

White ML, Zhou Y, Russo RS et al (2010) Carbonyl sulfide exchange in a temperate loblolly pine forest grown under ambient and elevated $\mathrm{CO}_{2}$. Atmos Chem Phys 10:547-561

$\mathrm{Xu} \mathrm{L}$, Baldocchi DD (2004) Seasonal variation in carbon dioxide exchange over a Mediterranean annual grassland in California. Agric For Meteorol 123:79-96. doi:10.1016/j. agrformet.2003.10.004

Xu X, Bingemer HG, Schmidt U (2002) The flux of carbonyl sulfide and carbon disulfide between the atmosphere and a spruce forest. Atmos Chem Phys 2:171-181. doi:10.5194/ acp-2-171-2002

Yi Z, Wang X, Sheng G et al (2007) Soil uptake of carbonyl sulfide in subtropical forests with different successional stages in south China. J Geophys Res 112:D08302 